\title{
Cost-benefit analysis for optimal DG placement in distribution systems by using elephant herding optimization algorithm
}

\author{
C. Hari Prasad ${ }^{1 *}$, K. Subbaramaiah ${ }^{2}$ and P. Sujatha ${ }^{3}$
}

\begin{abstract}
Distributed generations (DGs) are small generating plants which are connected to consumers in distribution systems to improve the voltage profile, stability improvement, reduction in power losses and economic benefits. The above benefits can be achieved by optimal placement of DGs. In this paper, a novel nature-inspired algorithm called elephant herding optimization algorithm is used to determine the optimal distributed generation size. It has been developed based on herding behaviour of elephant groups in nature. The proposed algorithm is tested on IEEE 15-, 33- and 69-bus test systems. The proposed algorithm with type III DG unit operating at 0.9 pf gives better results when compared with other methods in the literature.
\end{abstract}

Keywords: Elephant herding optimization algorithm, Power loss reduction method, Distributed generation placement, Radial distribution system, Loss reduction

\section{Introduction}

Distributed generation concept was aroused when the electricity was introduced as a commercial alternative for the energy. In distribution systems, the power flow is unidirectional and has radial structure. As the demand is increasing day by day, it faces several problems. About $70 \%$ losses are occurring at distribution level, while 30\% losses are occurring at transmission level. Hence distribution systems are main concern nowadays. The losses targeted at distribution level are about 7.5\%. Generally power sources like distributed generations (DGs), capacitor banks, etc. are used to reduce losses. Quite a lot of methods have been proposed in the literature for the placement of DGs.

To minimize line losses of power systems, it is crucially important to define the size and location of local generation to be placed. Proper location of DGs in power systems is important for obtaining their maximum potential benefits. The authors Zhang et al. (2018), Acharya et al. (2006) and Wang and Nehrir (2004) proposed an

*Correspondence: hariprasadchallaa@gmail.com

1 JNT University, Anatapuram, Andhra Pradesh, India

Full list of author information is available at the end of the article analytical expression to calculate the optimal size and an effective methodology to identify the corresponding optimum location for DG placement for minimizing the total power losses in primary distribution systems.

The authors Kaur and Jain (2017) proposed the optimal placement of multiple dispersed generators using multiobjective optimization. A new planning approach based on voltage stability index (VSI) together with improved loss minimization (LM) formulations was also presented in the literature (Kazmi and Shin 2017; Singh and Parida 2016; Singh and Goswami 2009; Kayal and Chanda 2013; Aman et al. 2012, 2013, 2014; Amanifar 2011; Hedayati et al. 2008).

The optimal placement and sizing of distributed generators for real power losses minimization in distribution systems over the past years were proposed with different algorithms called war optimization (Coelho et al. 2018), global criterion method (Bhattacharya et al. 2018), hybrid GMSA (Mohamed et al. 2018), a multi-objective evolutionary algorithm based on decomposition (MOEA/D) (Biswas et al. 2017), K-means clustering method (Penangsang et al. 2018), shuffled frog leaping algorithm (SFLA) (Suresh and Belwin Edward 2017), a combination of a fuzzy multi-objective approach and bacterial foraging 
optimization (BFO) as a meta-heuristic algorithm is used to solve the simultaneous reconfiguration and optimal sizing of DGs and shunt capacitors in a distribution system (Mohammadi et al. 2017), a multi-objective genetic algorithm (Tarôco et al. 2016), grey wolf optimizer (GWO) for multiple DG allocation (i.e. siting and sizing) in the distribution system (Sultana et al. 2016), shuffled bat algorithm (Yammani et al. 2016a), hybrid optimization algorithm (Yammani et al. 2016b), flower pollination algorithm (Sudabattula and Kowsalya 2016), hybrid big brunch big crunch algorithm (Saha and George Fernandez 2016), sensitivity analysis technique (Gopiya Naik et al. 2013), a modified teaching-learning-based optimization (MTLBO) algorithm (Martín García and Gil Mena 2013), harmony search algorithm (HSA) (Rao et al. 2013), combined genetic algorithm (GA)/particle swarm optimization (PSO) (Moradi and Abedini 2012), improved honey bee mating optimization (HBMO) algorithm (Niknam et al. 2011), multi-objective index-based approach (El-Zonkoly 2011), particle swarm optimization (PSO) (Táutiva et al. 2009; Kansal et al. 2013), a genetic algorithm (Masoum et al. 2004) capacitor placement, multi-objective particle swarm optimization (MOPSO) probability-based solar power DG into the distribution system (Mahesh et al. 2017a, b), state-of-the-art models and methods applied to the ODGP problem (Georgilakis and Hatziargyriou 2013; Abdulwahhab Abdulrazzaq et al. 2016; Warid et al. 2017) and a binary particle swarm optimization (BPSO) algorithm (Moshtagh et al. 2010).

Several performance evaluation indices such as active and reactive power loss indices, voltage deviation index, reliability index and shift factor indices are used to develop a novel multi-objective function (MOF). A novel MOF has been solved to find optimal sizing and placement of DGs using genetic algorithm, and particle swarm optimization technique was proposed in Bohre et al. (2016). Optimal allocation and operating point of DG units in radial distribution network considering load pattern had done in Sultana et al. (2017) and Hadavi et al. (2017). The authors Kalambe and Agnihotri (2014), Viral and Khatod (2012) and Li et al. (2018) give a bibliographical survey, general background and comparative analysis of three most commonly used techniques: (i) capacitor placement, (ii) feeder reconfiguration and (iii) DG allocation for loss minimization in distribution network.

Optimal and simultaneous siting and sizing of distributed generators and capacitor banks in distribution systems have attracted a lot of attention from distribution companies (Pereira et al. 2016). Techno-economic analysis is important in DG placement. Some of the papers (Tanwar and Khatod 2016, 2017; Muttaqi et al. 2016; Asadi et al. 2014; Mousavi and Mohammadi 2011; Payyala and Green 2006) address the issue of DG planning and has proposed different techniques for optimizing the DG size and location to minimize the overall investment and operational cost of the system. The installation of distributed generation power plants is common due to advantages such as system capacity release, voltage support and reduced energy losses in power networks (Dorahaki 2016). The authors Ameli et al. (2015) propose a novel comprehensive economic method for planning DG units which considers both the distribution company's (DisCo) and the DG owner's (DGO) profits simultaneously. The authors Kansal et al. (2017) present an profit/worth analysis approach for DG placement.

To the best of authors' knowledge, elephant herding optimization has not been proposed to optimal DG size with economic analysis in the literature.

\section{Problem formulation}

In the distribution system, more losses are there due to low voltage compared to transmission system. Copper losses are predominant in distribution system and this can be calculated as follows

$$
P_{\mathrm{loss}}=\sum_{i}^{n-1} I_{i}^{2} R_{i}
$$

where $I_{i}$ is current, $R_{i}$ is resistance and $n$ is number of buses. Objective taken in this paper is real power loss minimization. The voltage constraint is between the limits 0.9 to 1.05. The upper and lower limits of DG are 60 to 3000 , where the limits are in $\mathrm{kW}, \mathrm{kVAR}$ and $\mathrm{kVA}$ for type I, II and III DG, respectively.

\section{Power loss reduction method}

DG locations are obtained based on the power losses and their loss reductions in the system (Dinakara Prasad Reddy et al. 2018). Artificial intelligence technique is not involved in this method. The loss reductions at all the buses are calculated by compensating the total reactive power at each bus. The obtained loss reduction values are normalized into the range $[0,1]$ for simplification, and minimum and maximum loss reductions are noted (Dinakara Prasad Reddy et al. 2018).

Real power loss in the $k$ th line is given by $\left[I_{k}^{2}\right] \times\left[R_{k}\right]$ and can also be expressed as follows

$$
\operatorname{PL}(j)=\frac{\left(P^{2}(j)+Q^{2}(j)\right) \times R_{k}}{V(j)^{2}}
$$

Similarly reactive power loss in the $k$ th line is given by $\left[I_{k}^{2}\right] \times\left[X_{k}\right]$ and can also be expressed as follows

$$
\mathrm{QL}(j)=\frac{\left(P^{2}(j)+Q^{2}(j)\right) \times X_{k}}{V(j)^{2}}
$$


Table 1 PLI values for 15-bus system

\begin{tabular}{lc}
\hline PLI values & Bus number \\
\hline 1.0000 & 15 \\
0.9865 & 11 \\
0.9602 & 4 \\
0.8353 & 7 \\
0.8000 & 6 \\
0.4611 & 12 \\
0.4119 & 14 \\
0.3266 & 8 \\
0.3205 & 3 \\
\hline
\end{tabular}

where $I_{k}$ is the current flowing through $k$ th line. $V[j]$ is the voltage at the bus ' $j$ '. $P[j]=$ net active power supplied beyond the bus ' $j$ '. $Q[j]=$ net reactive power supplied beyond the bus ' $j$ '. $R_{k}$ and $X_{k}$ are the resistance and reactance of the $k$ th line.

After finding the real and reactive power losses for all the buses, the loss reduction factors can be calculated using the following equation.

$$
\operatorname{PLI}(b)=\frac{\operatorname{LR}(b)-\mathrm{LR}(\min )}{\operatorname{LR}(\max )-\operatorname{LR}(\min )}
$$

where $b$ is the number of the bus. $\operatorname{LR}(b)$ is the loss reduction at bus $b . \mathrm{LR}(\min )$ and $\mathrm{LR}(\max )$ are the minimum and maximum loss reduction values. Power loss index (PLI) represent the loss reduction of that particular bus with respect to the maximum and minimum loss reductions in the system so that when the DGs are placed on the buses with high power loss index, maximum loss reduction can be expected.

\section{Optimal locations for 15-bus system}

The proposed PLR method is applied to IEEE 15-bus system. Optimal locations are identified based on the PLI values (Table 1 ).

First best location for 15-bus system is 15 .

\section{Optimal locations for 33-bus system}

The proposed PLR method is applied to 33-bus system. Optimal locations are identified based on the PLI values (Table 2).

Best location for 33-bus system is 30 .

\section{Optimal locations for 69-bus system}

The proposed PLR method is applied to 69-bus system. Optimal locations are identified based on the PLI values (Table 3).

First best location for 69-bus system is 61 .
Table 2 PLI values for first ten elements of 33-bus system

\begin{tabular}{ll}
\hline PLI values & Bus number \\
\hline 1.0000 & 30 \\
0.2176 & 32 \\
0.1531 & 31 \\
0.1371 & 29 \\
0.1317 & 14 \\
0.1283 & 8 \\
0.1195 & 7 \\
\hline
\end{tabular}

Table 3 PLI values for first ten elements of 69-bus system

\begin{tabular}{ll}
\hline PLI values & Bus number \\
\hline 1.0000 & 61 \\
0.2669 & 64 \\
0.1018 & 59 \\
0.0736 & 65 \\
0.0570 & 21 \\
0.0547 & 12 \\
0.0494 & 11 \\
\hline
\end{tabular}

\section{Elephant herding optimization}

\section{Herding behaviour of elephants}

African and Asian elephants are two of traditionally recognized species of the one of the largest mammals on earth. Multi-purpose usage of the long trunk of elephant like breathing, sucking water and fetching objects had the most significant feature. Elephants are social animals where females and calves live together as a herd. Different clan elephants are present in the group where the oldest leads them. A clan consists of one or more females with their kids. Females live in groups, and males live separately; they leave the family group after growing group. Through lowfrequency vibrations, the male elephants maintain contact with female elephants in the clan. In this paper, for the formation of general-purpose global optimization method, two operators are derived from the herding behaviour of the elephants (Wang et al. 2015).

\section{Elephant herding optimization}

Three common rules are formed from the herding behaviour of the elephants to solve all types of global optimization problems.

1. The elephant population is composed of some clans where each of the clan has fixed number of elephants. 
2. In each generation, a certain number of male elephants live unaccompanied leaving their family group or herd.

3. A matriarch acts as the leader for elephants living in a clan.

\section{Clan updating operator}

As the elephants live together under the leadership of the matriarch, the next position of each of the elephant is dependent on the matriarch of the clan. In clan for elephant $j$, it is given as

$$
x_{n e w, c i, j}=x_{c i, j}+\alpha \times\left(x_{b e s t, c i}-x_{c i, j}\right) \times r
$$

where for elephant $j$ in clan $c i, x_{n e w, c i, j}$ and $x_{c i, j}$ are newly updated and old positions, respectively. The influence of the matriarch in $x_{c i, j}$ is taken on a scale factor $\alpha \in[0,1]$. The fittest elephant in the clan is $x_{b e s t, c i}$. Uniform distribution is used in this algorithm and $r \in[0,1]$. The equation for updating the fittest elephant matriarch is given below

$$
x_{n e w, c i, j}=\beta \times x_{\text {centre }, c i}
$$

The factor that influences the $x_{\text {centre,ci }}$ on $x_{n e w, c i, j}$ is $\beta \in[0,1]$. From the information collected from all the elephants in the clan ci, the new member $x_{n e w, c i, j}$ is generated in the clan. For the $d$ th dimension having $x_{c e n t r e, c i}$ as the centre of the clan, it is calculated using

$$
x_{\text {centre }, c i, d}=\frac{1}{n} \times \sum_{j=1}^{n_{c i}} x_{c i, j, d}
$$

The $d$ th dimension has the limits $1 \leq d \leq D$, where $D$ is its total dimension. The number of elephants in the clan is given by $n_{c i}$. $d$ th elephant individual is given by $\sum_{j=1}^{n_{c i}} x_{c i, j, d}$. The centre of clan $x_{c e n t r e, c i, d}$ is calculated from the above equation. The clan updating operator can be formulated as shown in Algorithm 1.

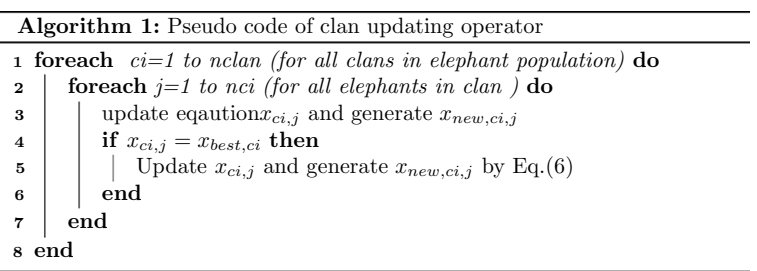

\section{Separating operator}

After reaching puberty, the male elephants will leave their family group and live solitarily. While solving optimization problems, a separation operator can be modelled for this separating process. It is assumed that the elephant individuals with least fitness will implement the separating operator for further improvement in search ability of $\mathrm{EHO}$ algorithm and is calculated as

$$
x_{\text {worst }, c i}=x_{\min }+\left(x_{\max }-x_{\min }+1\right) \times \text { rand }
$$

where the upper and lower bound positions of elephants are $x_{\max }$ and $x_{\min }$, respectively. The worst elephant individual of clan ci is given by $x_{\text {worst }, c i}$. The uniform distribution is in the range $[0,1]$ and stochastic distribution which is given by rand $\in[0,1]$. The separating operator can be formed as shown in Algorithm 2.

\begin{tabular}{l}
\hline Algorithm 2: Pseudo code of separating operator \\
\hline $\mathbf{1}$ foreach ci=1 to nclan (for all clans in elephant population) do \\
$\mathbf{2} \mid$ Replace the worst elephant in clan ci by Eq.(8). \\
$\mathbf{3}$ end \\
\hline
\end{tabular}

EHO method is developed and updated based on the description of clan updating operator and its mainframe is shown in Algorithm 3.

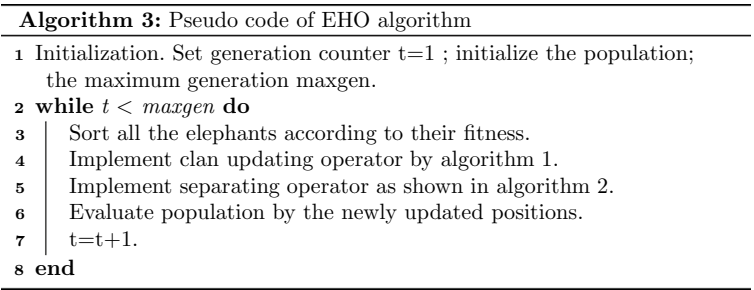

\section{Results and discussion}

EHO algorithm for the application of DG planning problem to obtain DG size and economic analysis is presented in this section. IEEE 15-, 33- and 69-bus test systems are evaluated using Matlab. The parameters using in EHO algorithm are $\alpha=0.5, \beta=0.1$, popsize $=50$, Maxgen $=60$.

\section{Techno-economic analysis}

The real and reactive power loss, minimum voltage level and the cost of energy loss as well as cost of power obtained from DGs have been provided for 15-, 33- and 69-bus test systems at unity and $0.9 \mathrm{pf}$ lag with comparisons. The cost of energy losses and cost component of DG power has been calculated based on the mathematical model represented as

\section{Cost of energy losses (CL)}

The annual cost of energy loss is given by (Murthy and Kumar 2013; Suresh and Belwin 2018) 


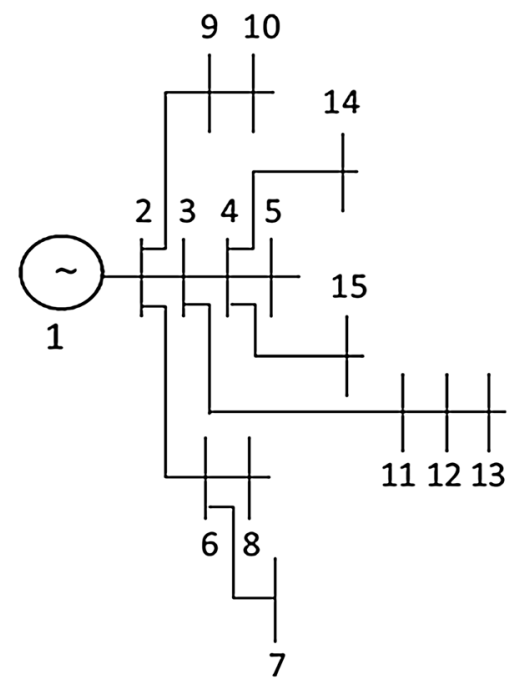

Fig. 1 Single line diagram of 15-bus system

$$
\mathrm{CL}=(\mathrm{TPL}) *(\mathrm{Kp}+\mathrm{Ke} * \mathrm{Lsf} * 8760) \$
$$

where TPL: total real power losses, Kp: annual demand cost of power loss $(\$ / \mathrm{kW})$, Ke: annual cost of energy loss ( $\$ / \mathrm{kW} \mathrm{h})$ and Lsf: loss factor.

Loss factor is expressed in terms of load factor (Lf) as below

$$
\mathrm{Lsf}=k * \mathrm{Lf}+(1-k) * \mathrm{Lf}^{2}
$$

The values taken for the coefficients in the loss factor calculation are: $k=0.2, \mathrm{Lf}=0.47, \mathrm{Kp}=57.6923 \$ / \mathrm{kW}$, $\mathrm{Ke}=0.00961538 \$ / \mathrm{kWh}$.

\section{Cost component of $D G$ for real and reactive power}

$$
C(P d g)=a * P d g^{2}+b * P d g+c \$ / \mathrm{MWh}
$$

Cost coefficients are taken as: $a=0, b=20, c=0.25$.
Cost of reactive power supplied by DG is calculated based on maximum complex power supplied by DG as

$$
\begin{aligned}
& C(Q d g)=\left[\operatorname{Cost}(S g \max )-\operatorname{Cost}\left(\sqrt{S g \max ^{2}-Q g^{2}}\right)\right] * k \\
& S g \max =\frac{P g \max }{\cos \phi}
\end{aligned}
$$

Pgmax $=1.1 * \mathrm{pg}$, the power factor, has been taken 1 at unity power factor and $0.9(\mathrm{lag})$ at lagging power factor to carry out the analysis. $k=0.05-0.1$. In this paper, the value of factor $k$ is taken as 0.1 .

\section{IEEE 15-bus system}

The single line diagram of IEEE 15-bus distribution system (Baran and Wu 1989) is shown in Fig. 1.

For IEEE 15-bus system without installation of DG, the real and reactive power losses are $61.7933 \mathrm{~kW}$ and 57.2969 kVAR, respectively. With the installation of DG at unity pf real, reactive power losses are $42.24 \mathrm{~kW}$ and 39.99 kVAR, respectively. With DG installation operating at $0.9 \mathrm{pf}$ lag, the real and reactive power losses are $28.05 \mathrm{~kW}$ and 22.94 kVAR, respectively. Comparison of results is shown in Table 4. The optimal location for 15 -bus test system is 15 . The minimum voltage is more in case of type III DG operating at 0.9 pf. The losses are also lower with DG type III operating at $0.9 \mathrm{pf}$ lag when compared to DG operating at upf. This is because both real and reactive powers are supplied by the DG at lagging pf. Reactive power is not supplied by type III DG when operating at unity pf. Hence losses are higher when compared to DG operating at $0.9 \mathrm{pf}$ lagging. The cost of energy losses, cost of PDG and cost of QDG are shown in Table 4. From the table, the cost of energy losses is reduced from 4970.3 \$ to 2256 \$ when DG is operating

\begin{tabular}{|c|c|c|c|c|c|}
\hline & Without DG & $\begin{array}{l}\text { With DG at } 0.9 \text { pf (Dinakara } \\
\text { Prasad Reddy et al. 2017) }\end{array}$ & $\begin{array}{l}\text { Proposed } \\
\text { method at } 0.9 \mathrm{pf}\end{array}$ & $\begin{array}{l}\text { With DG at UPF (Dinakara } \\
\text { Prasad Reddy et al. 2017) }\end{array}$ & $\begin{array}{l}\text { Proposed } \\
\text { method } \\
\text { at upf }\end{array}$ \\
\hline DG location & - & 6 & 15 & 6 & 15 \\
\hline DG size (kVA) & - & 907.785 & 910.5 & 675.248 & 681.1 \\
\hline $\mathrm{TLP}(\mathrm{kW})$ & 61.7933 & 33.385 & 28.05 & 45.8035 & 42.24 \\
\hline TLR (kVAR) & 57.2969 & 29.89 & 22.94 & 41.88 & 39.99 \\
\hline Vmin (p.u.) & 0.9445 & 0.959 & 0.971 & 0.9527 & 0.9596 \\
\hline Cost of energy losses (\$) & 4970.3 & 2685.31 & 2256 & 3684.18 & 3397 \\
\hline Cost of PDG (\$/MW h) & - & 16.5404 & 16.598 & 13.754 & 13.87 \\
\hline Cost of QDG (\$/MVAR h) & - & 1.8656 & 1.872 & & _ \\
\hline
\end{tabular}
at $0.9 \mathrm{pf}$ lag and it is reduced to 3397 \$ when operating at unity pf. Cost of energy losses are less when DG is operating at $0.9 \mathrm{pf}$. When compared with the method

Table 4 Results for 15-bus system 


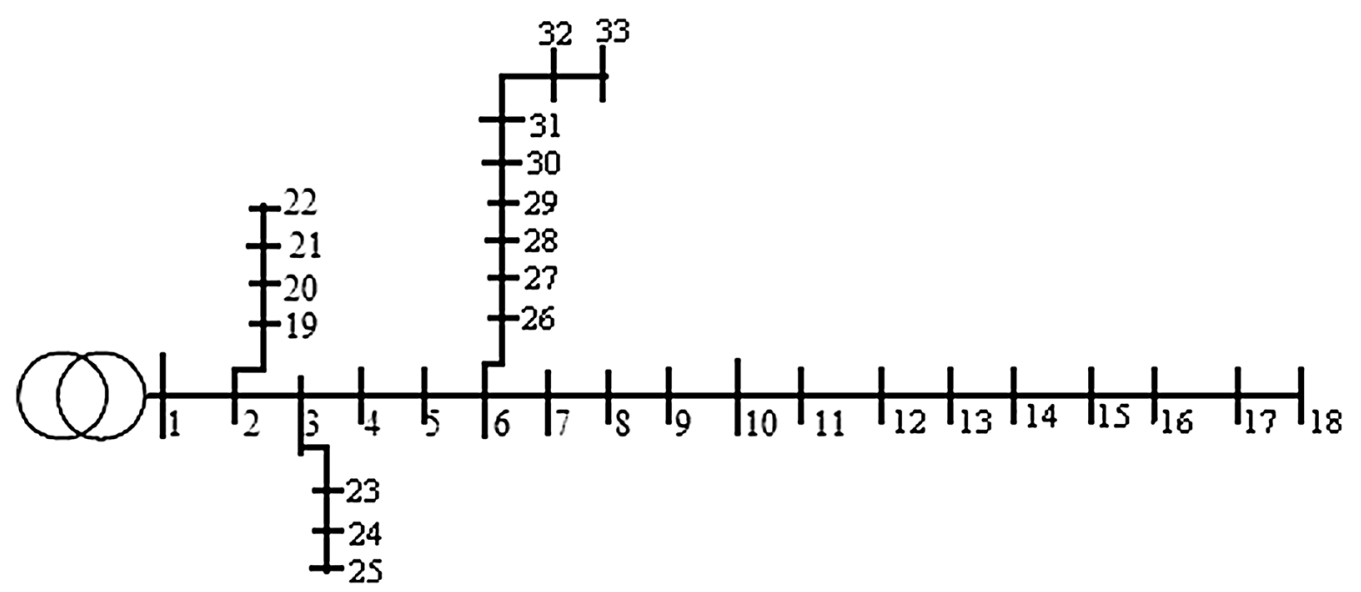

Fig. 2 Single line diagram of 33-bus system

(Dinakara Prasad Reddy et al. 2017), the proposed power loss reduction combined with EHO algorithms gives better results.

\section{Results for 33-bus distribution system}

The single line diagram of IEEE 33-bus distribution system (Baran and Wu 1989) is shown in Fig. 2.

For 33-bus system without installation of DG, the real and reactive power losses are $211 \mathrm{~kW}$ and $143 \mathrm{kVAR}$, respectively. The real and reactive power from the substation is $3926 \mathrm{~kW}$ and $2443 \mathrm{kVAR}$. With installation of DG at unity pf, the real and reactive power losses are $125 \mathrm{~kW}$ and $89.3 \mathrm{kVAR}$, respectively. Also the real and reactive power from the substation is decreased to 2375 $\mathrm{kW}$ and $2443 \mathrm{kVAR}$. With DG operating at $0.9 \mathrm{pf}$ lag, the real and reactive power losses are $78.4 \mathrm{~kW}$ and 58.97 kVAR, respectively. The real and reactive powers from the substation become $218 \mathrm{~kW}$ and $1593 \mathrm{kVAR}$. The cost of energy losses, cost of PDG and cost of QDG are also shown in Tables 5 and 6 . From table, the cost of energy

Table 5 Results for 33-bus system with DG at upf

\begin{tabular}{llll}
\hline & Without DG & $\begin{array}{l}\text { Method (Murthy } \\
\text { and Kumar 2013) }\end{array}$ & $\begin{array}{c}\text { Method in Dinakara Prasad } \\
\text { Reddy et al. (2017) }\end{array}$ \\
\hline DG location & - & 16 & 6 \\
DG size (kW) & - & 1000 & 2590.2 \\
Total real power loss (TLP) (kW) & 211 & 136.7533 & 111.0338 \\
Total reactive power (TLR) loss (kVAR) & 143 & 92.6599 & 81.6859 \\
Vmin (p.u.) & 0.904 & 0.9318 & 0.9424 \\
Cost of energy losses (\$) & 16982.6 & $11,007.9$ & 8930.65 \\
Cost of PDG (\$/MW $h)$ & - & 20.25 & 52.05 \\
\hline
\end{tabular}

Table 6 Results for 33-bus system with DG at 0.9 pf

\begin{tabular}{|c|c|c|c|}
\hline & Method (Murthy and Kumar 2013) & $\begin{array}{l}\text { Method in Dinakara Prasad Reddy et al. } \\
(2017)\end{array}$ & Proposed method \\
\hline DG location & 16 & 6 & 30 \\
\hline DG size (kVA) & 1200 & 3073.5 & 1939.3 \\
\hline TLP $(k W)$ & 112.7864 & 70.8652 & 78.4 \\
\hline TLR (kVAR) & 77.449 & 56.7703 & 58.97 \\
\hline Vmin (p.u.) & 0.9378 & 0.9566 & 0.9386 \\
\hline Cost of energy losses (\$) & 9078.7686 & 5700.01 & 6308.8 \\
\hline Cost of PDG (\$/MW h) & 21.85 & 55.5 & 35.102 \\
\hline Cost of QDG (\$/MVAR h) & 2.1207 & 6.2 & 3.928 \\
\hline
\end{tabular}




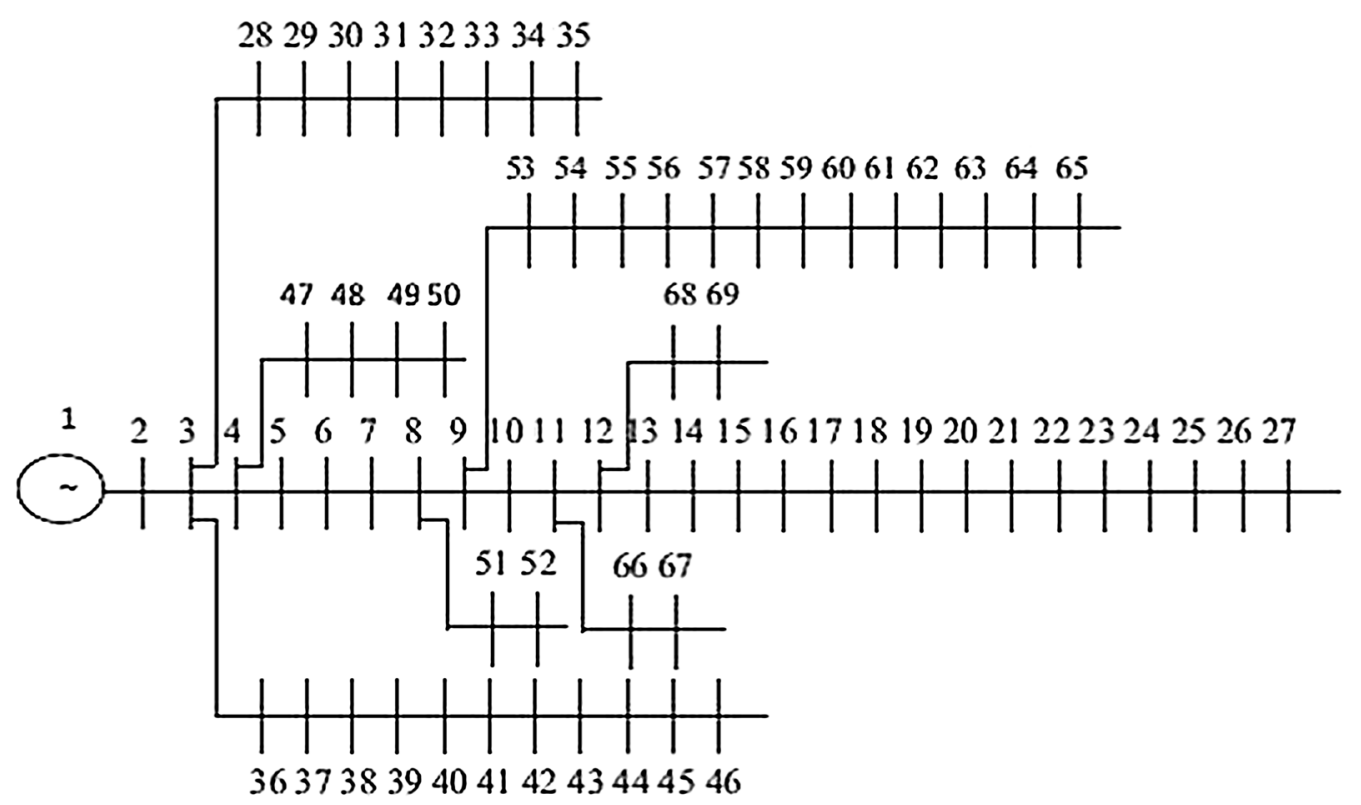

Fig. 3 Single line diagram of $69-$ bus system

Table 7 Results for 69-bus system with DG at upf

\begin{tabular}{lllll}
\hline & Without DG & $\begin{array}{l}\text { Method (Murthy } \\
\text { and Kumar 2013) }\end{array}$ & $\begin{array}{l}\text { Method in Dinakara Prasad } \\
\text { Reddy et al. (2017) }\end{array}$ & $\begin{array}{l}\text { Proposed method } \\
\text { DG location }\end{array}$ \\
DG size (kW) & - & 65 & 61 & 61 \\
TLP (kW) & - & 1450 & 1872.7 & 1873.6 \\
TLR (kVAR) & 225 & 112.0217 & 83.22 & 83.23 \\
Vmin (p.u.) & 102.1091 & 55.1172 & 40.57 & 40.54 \\
Cost of energy losses $(\$)$ & 0.909253 & 0.9660621 & 0.9685 & 0.9683 \\
Cost of Pdg (\$/MW h) & $18,101.7621$ & 9017.2139 & 6694 & 6693.8 \\
\hline
\end{tabular}

losses is reduced from $16982.57 \$$ to 6308.8 \$ when DG is operating at $0.9 \mathrm{pf}$ lag and it reduced to $10067.3 \$$ when operating at unity pf. Cost of energy losses is less when DG is operating at $0.9 \mathrm{pf}$. When compared with Murthy and Kumar (2013), the proposed method gives better results.

\section{Results for 69-bus distribution system}

The IEEE 69-bus distribution system with $12.66-\mathrm{kV}$ base voltage (Baran and Wu 1989) is shown in Fig. 3.

Without DG installation, the real and reactive power losses are $225 \mathrm{~kW}$ and $102.1091 \mathrm{kVAR}$, respectively. With the installation of DG at unity pf, the real and reactive power losses are $83.2261 \mathrm{~kW}$ and $40.54 \mathrm{kVAR}$, respectively. With DG operating at $0.9 \mathrm{pf}$ lag, the real and reactive power losses are $27.95 \mathrm{~kW}$ and $16.46 \mathrm{kVAR}$.

The losses obtained are lower when DG operating at lagging power factor when compared to unity power factor DG. This is due to reactive power available in lagging power factor DG. The cost of energy losses, cost of PDG and cost of QDG are also shown in Tables 5 and 6. From table the cost of energy losses is reduced from 18,101.7 $\$$ to 2249.4 \$ when DG is operating at $0.9 \mathrm{pf}$ lag and it reduced to $6693.8 \$$ when operating at unity pf. The cost of energy losses are less when DG is operating at $0.9 \mathrm{pf}$. 
Table 8 Results for 69-bus system with DG at 0.9 pf

\begin{tabular}{llll}
\hline & Method (Murthy and Kumar 2013) & $\begin{array}{l}\text { Method in Dinakara Prasad Reddy et al. } \\
\text { (2017) }\end{array}$ & Proposed method \\
\hline DG location & 65 & 61 & 61 \\
DG size (kVA) & 1750 & 2217.3 & 2216.3 \\
TLP (kW) & 65.4502 & 27.9636 & 27.95 \\
TLR (kVA) & 35.625 & 16.4979 & 16.46 \\
Vmin (p.u.) & 0.969302 & 0.9728 & 0.9724 \\
Cost of energy losses (\$) & 5268.4297 & 2249.2 & 2249.4 \\
Cost of PDG (\$MW h) & 31.75 & 40.1 & 40.0916 \\
Cost of QDG (\$/MVAR h) & 3.083 & 4.48 & 4.4824 \\
\hline
\end{tabular}

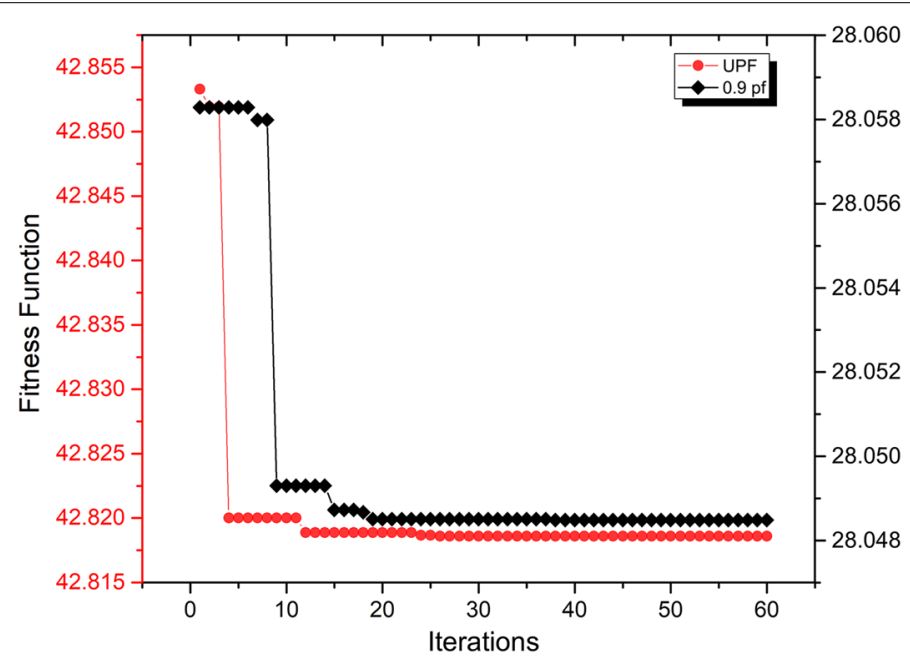

Fig. 4 Convergence characteristics of 15-bus system

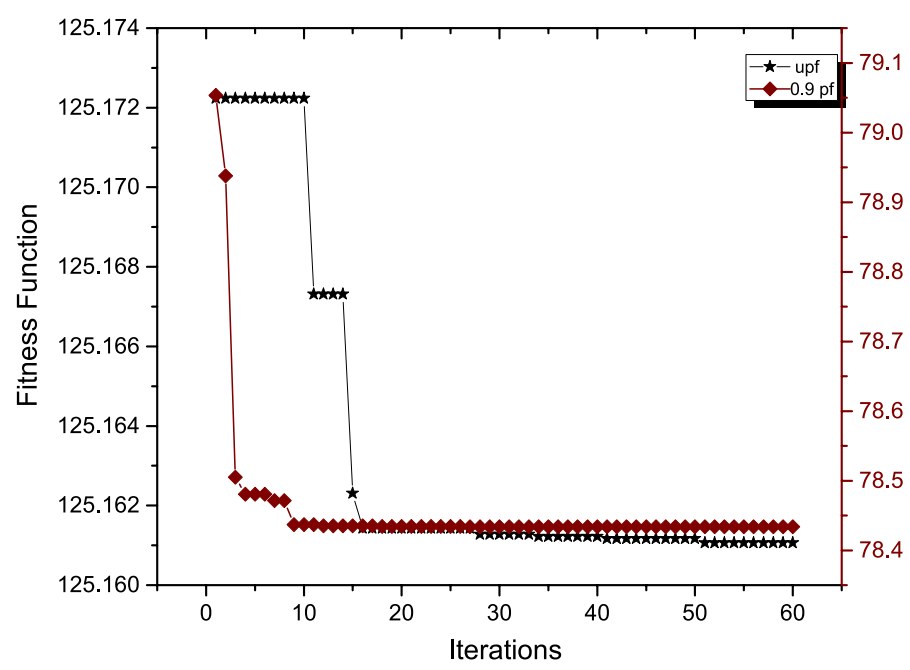

Fig. 5 Convergence characteristics of 33-bus system 


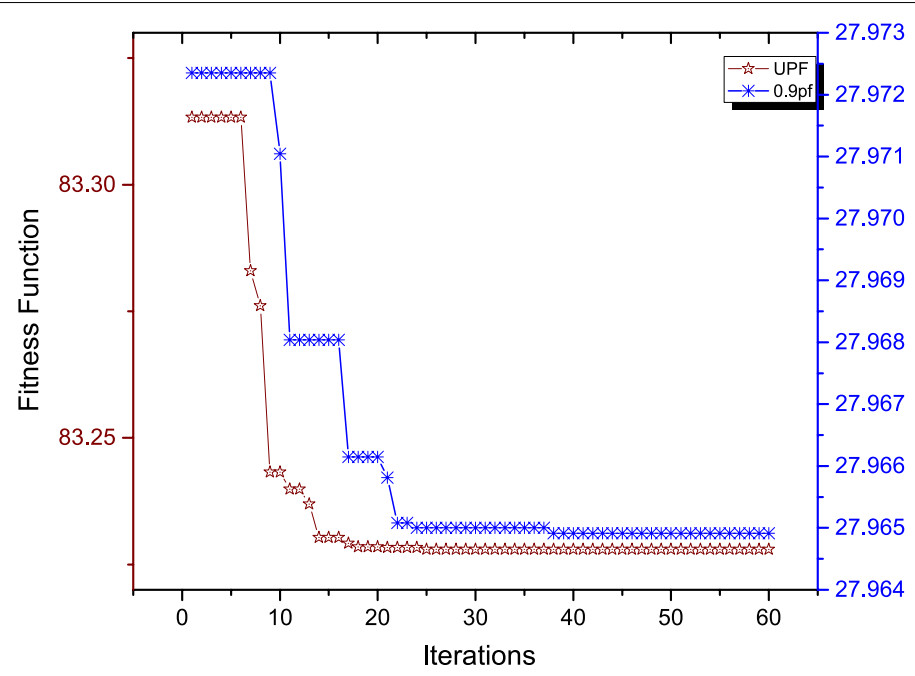

Fig. 6 Convergence characteristics of 69-bus system

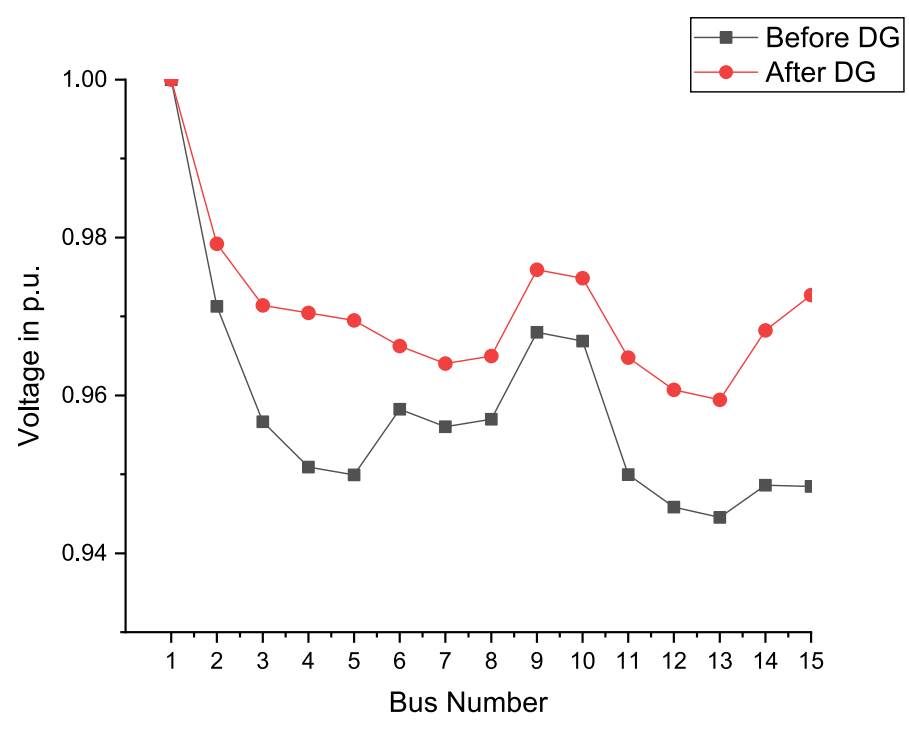

Fig. 7 Voltage profile of 15-bus system

The results obtained are given in Tables 7 and 8 . Better results are obtained while considering reactive power of DG when comparison with unity pf. Convergence characteristics of EHO algorithm for IEEE test systems with upf and 0.9 pf are shown in Figs. 4, 5 and 6, respectively.

The voltage profile is also improved with DGs at lagging power factor, and it is shown in Figs. 7, 8 and 9. The voltage profile obtained for the system with DG operating at $0.9 \mathrm{pf}$ is better compared to the voltage profile obtained with DGs at unity power factor. The power loss comparison is shown in Fig. 10.

\section{Conclusions}

In this paper, a novel nature-inspired algorithm called elephant herding optimization is used to determine the optimal DG unit's size. It has been developed based on herding behaviour of elephant groups in nature. The study is carried out on two types of DG that are DG operating at unity power factor and DG operating at 0.9 power factor lag. The results have been obtained for real and reactive power losses, voltage profile, cost component for real power and reactive power obtained from 


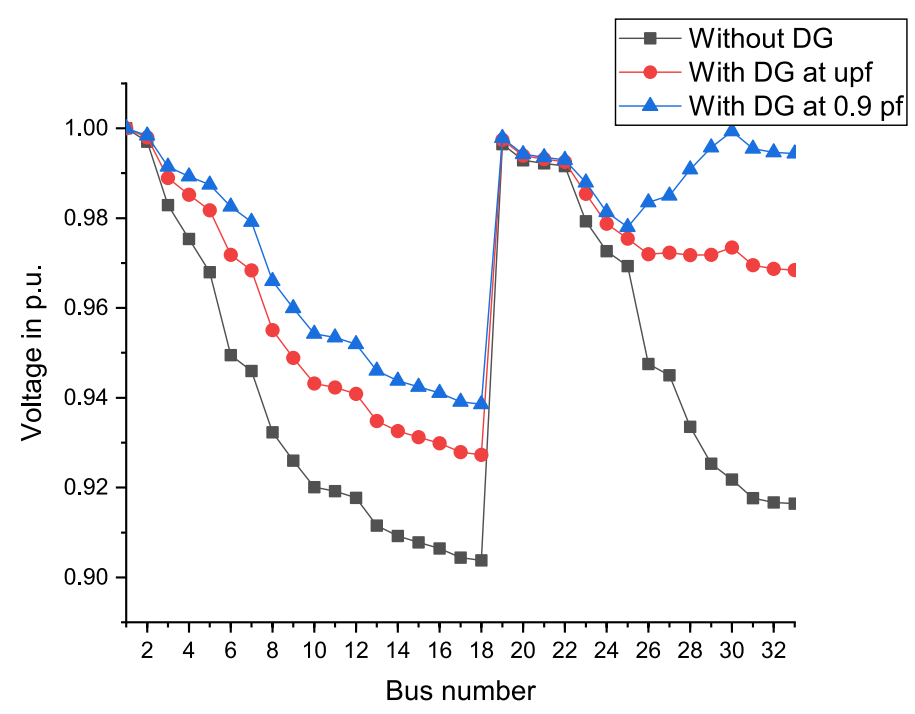

Fig. 8 Voltage profile of 33-bus system

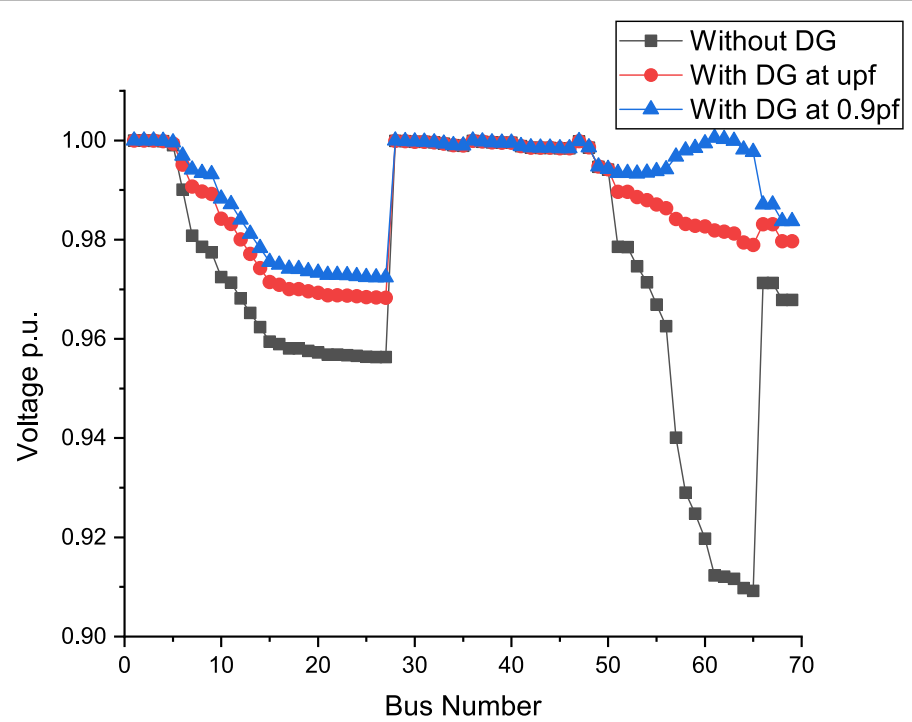

Fig. 9 Voltage profile of 69-bus system

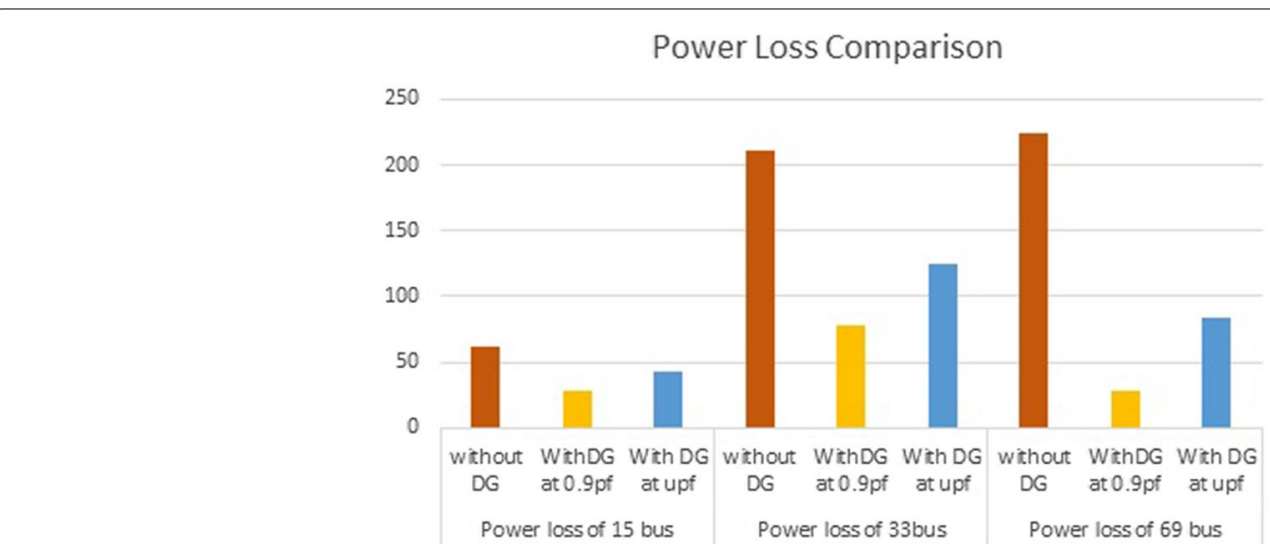

Fig. 10 Power loss comparison 
DGs, and their sizes. We can conclude that there is much reduction in real, reactive power losses and improvement in voltage profile with DG at $0.9 \mathrm{pf}$ lag due to its reactive power supply to the system. Therefore, DG operating at lagging power factor and supplying reactive power to the system is giving better results than DG at unity power factor. From the results, it can be concluded that with the combination of power loss index method and EHO algorithm is giving overall better results when compared with other algorithms.

\section{Abbreviations \\ $\alpha$ : Scale factor; D: Dimension; Maxgen: Maximum generations; TPL: Total real power losses; Kp: Annual demand cost of power loss ( $\$ / \mathrm{kW})$; Ke: Annual cost} of energy loss ( $\$ / \mathrm{kW}$ h); Lsf: Loss factor.

\section{Authors' contributions}

CHP carried out the literature survey and participated in DG location section. CHP and KS participated in the study on different nature-inspired algorithms for DG sizing. CHP carried out the DG sizing algorithm design and mathematical modelling. CHP, KS and PS participated in the assessment of the study and performed the analysis. CHP and PS participated in the sequence alignment and drafted the manuscript. All authors read and approved the final manuscript.

\section{Funding}

Funding information is not applicable, or no funding was received.

\section{Availability of data and materials}

Availability of data and materials is not applicable.

\section{Competing interests}

The authors declare that they have no competing interests.

\section{Author details}

${ }^{1}$ JNT University, Anatapuram, Andhra Pradesh, India. ${ }^{2}$ YITS, Tirupati, India.

${ }^{3}$ Department of EEE, JNT University, Anatapuram, Andhra Pradesh, India.

Received: 7 June 2018 Accepted: 10 June 2019

Published online: 26 June 2019

\section{References}

Abdulwahhab Abdulrazzaq, A., Eremia, M., Toma, L., \& Mandiș, C. A. (2016). Optimal distributed generators placement in a radial distribution network. UPB Scientific Bulletin, Series C: Electrical Engineering and Computer Science, 78(2), 261-272.

Acharya, N., Mahat, P., \& Mithulananthan, N. (2006). An analytical approach for $\mathrm{dg}$ allocation in primary distribution network. International Journal of Electrical Power and Energy Systems, 28(10), 669-678.

Amanifar, O. (2011). Optimal distributed generation placement and sizing for loss and THD reduction and voltage profile improvement in distribution systems using particle swarm optimization and sensitivity analysis.

Aman, M. M., Jasmon, G. B., Bakar, A. H. A., \& Mokhlis, H. (2013). A new approach for optimum DG placement and sizing based on voltage stability maximization and minimization of power losses. Energy Conversion and Management, 70, 202-210.

Aman, M. M., Jasmon, G. B., Bakar, A. H. A., \& Mokhlis, H. (2014). A new approach for optimum simultaneous multi-DG distributed generation units placement and sizing based on maximization of system loadability using HPSO (hybrid particle swarm optimization) algorithm. Energy, 66, 202-215.

Aman, M. M., Jasmon, G. B., Mokhlis, H., \& Bakar, A. H. A. (2012). Optimal placement and sizing of a DG based on a new power stability index and line losses. International Journal of Electrical Power and Energy Systems, 43(1), 1296-1304.
Ameli, A., Farrokhifard, M., Ahmadifar, A., \& Haghifam, M.-R. (2015). Distributed generation planning based on the distribution company's and the DG owner's profit maximization. International Transactions on Electrical Energy Systems, 25(2), 216-232

Asadi, A., Fotuhi-Friuzabad, M., \& Moeini-Aghtaie, M. (2014). Techno-economic considerations on distributed generations (DGs) planning studies in power distribution systems, pp. 82-87.

Baran, M. E., \& Wu, F. F. (1989). Optimal sizing of capacitors placed on a radialdistribution system. leee Transactions on Power Delivery, 4(1), 735-743.

Bhattacharya, M., Sivasubramani, S., \& Roy, A. (2018). Multiobjective placement and sizing of distributed generations in distribution system using global criterion method. International Transactions on Electrical Energy Systems, 28(1), e2471.

Biswas, P. P., Mallipeddi, R., Suganthan, P. N., \& Amaratunga, G. A. J. (2017). A multiobjective approach for optimal placement and sizing of distributed generators and capacitors in distribution network. Applied Soft Computing Journal, 60, 268-280.

Bohre, A. K., Agnihotri, G. \& Dubey, M. (2016). Optimal sizing and sitting of DG with load models using soft computing techniques in practical distribution system. IET Generation, Transmission and Distribution, 10(11), 2606-2621.

Coelho, F. C. R., da Silva Junior, I. C., Dias, B. H., \& Peres, W. B. (2018). Optimal distributed generation allocation using a new metaheuristic. Journal of Control, Automation and Electrical Systems, 29(1), 91-98.

Dinakara Prasad Reddy, P., Veera Reddy, V. C., \& Gowri Manohar, T. (2017). Whale optimization algorithm for optimal sizing of renewable resources for loss reduction in distribution systems. Renewables: Wind, Water, and Solar, 4(1), 3.

Dinakara Prasad Reddy, P., Veera Reddy, V. C., \& Gowri Manohar, T. (2018). Optimal renewable resources placement in distribution networks by combined power loss index and whale optimization algorithms. Journal of Electrical Systems and Information Technology, 5(2), 175-191.

Dorahaki, S. (2016). Optimal DG placement with the aim of profits maximization. Indonesian Journal of Electrical Engineering and Computer Science, 1(2), 249-254.

El-Zonkoly, A. M. (2011). Optimal placement of multi-distributed generation units including different load models using particle swarm optimization. Swarm and Evolutionary Computation, 1(1), 50-59.

Georgilakis, P. S., \& Hatziargyriou, N. D. (2013). Optimal distributed generation placement in power distribution networks: Models, methods, and future research. IEEE Transactions on Power Systems, 28(3), 3420-3428.

Gopiya Naik, S., Khatod, D. K., \& Sharma, M. P. (2013). Optimal allocation of combined DG and capacitor for real power loss minimization in distribution networks. International Journal of Electrical Power and Energy Systems, 53, 967-973.

Hadavi, S., Zoghi, A., Vahidi, B., Gharehpetian, G. B., \& Hosseinian, S. H. (2017). Optimal allocation and operating point of DG units in radial distribution network considering load pattern. Electric Power Components and Systems, 45(12), 1287-1297.

Hedayati, H., Nabaviniaki, S. A., \& Akbarimajd, A. (2008). A method for placement of DG units in distribution networks. IEEE Transactions on Power Delivery, 23(3), 1620-1628.

Kalambe, S. \& Agnihotri, G. (2014). Loss minimization techniques used in distribution network: Bibliographical survey. Renewable and Sustainable Energy Reviews, 29, 184-200.

Kansal, S., Kumar, V., \& Tyagi, B. (2013). Optimal placement of different type of DG sources in distribution networks. International Journal of Electrical Power and Energy Systems, 53(1), 752-760.

Kansal, S., Tyagi, B., \& Kumar, V. (2017). Cost-benefit analysis for optimal distributed generation placement in distribution systems. International Journal of Ambient Energy, 38(1), 45-54.

Kaur, N. \& Jain, S. K. (2017). Multi-objective optimization approach for placement of multiple dgs for voltage sensitive loads. Energies, 10(11), 1733.

Kayal, P., \& Chanda, C. K. (2013). Placement of wind and solar based DGs in distribution system for power loss minimization and voltage stability improvement. International Journal of Electrical Power and Energy Systems, 53, 795-809.

Kazmi, S. A. A., \& Shin, D. R. (2017). Dg placement in loop distribution network with new voltage stability index and loss minimization condition based planning approach under load growth. Energies, 10(8), 1203. 
Li, Y., Feng, B., Li, G., Qi, J., Zhao, D., \& Yunfei, M. (2018). Optimal distributed generation planning in active distribution networks considering integration of energy storage. Applied Energy, 210, 1073-1081.

Mahesh, K., Nallagownden, P., \& Elamvazuthi, I. (2017a). Optimal placement and sizing of renewable distributed generations and capacitor banks into radial distribution systems. Energies, 10(6), 811.

Mahesh, K., Nallagownden, P., \& Elamvazuthi, I. (2017b). Multi-objective PSO based optimal placement of solar power DG in radial distribution system. Journal of Electrical Systems, 13(2), 322-331.

Martín García, J. A., \& Gil Mena, A. J. (2013). Optimal distributed generation location and size using a modified teaching-learning based optimization algorithm. International Journal of Electrical Power and Energy Systems, 50(1), 65-75.

Masoum, M. A. S., Ladjevardi, M., Jafarian, A., \& Fuchs, E. F. (2004). Optimal placement, replacement and sizing of capacitor banks in distorted distribution networks by genetic algorithms. IEEE Transactions on Power Delivery, 19(4), 1794-1801.

Mohamed, E. A., Mohamed, A.-A. A., \& Mitani, Y. (2018). Hybrid GMSA for optimal placement and sizing of distributed generation and shunt capacitors. Journal of Engineering Science and Technology Review, 11(1), 55-65.

Mohammadi, M., Rozbahani, A. M., \& Bahmanyar, S. (2017). Power loss reduction of distribution systems using bfo based optimal reconfiguration along with DG and shunt capacitor placement simultaneously in fuzzy framework. Journal of Central South University, 24(1), 90-103.

Moradi, M. H., \& Abedini, M. (2012). A combination of genetic algorithm and particle swarm optimization for optimal DG location and sizing in distribution systems. International Journal of Electrical Power and Energy Systems, 34(1), 66-74.

Moshtagh, J., Jalali, A., \& Karimizadeh, K. (2010). Optimum placement and sizing of DG using binary PSO algorithm to achieve the minimum electricity cost for consumers. International Review of Electrical Engineering, 5(6), 2873-2881.

Mousavi, S. H., \& Mohammadi, M. (2011). Economic analysis of optimal planning of distribution system in presence of DGs with considering power quality indices with fuzzy logic algorithm (FLA). Australian Journal of Basic and Applied Sciences, 5(8), 889-898.

Murthy, V. V. S. N., \& Kumar, A. (2013). Comparison of optimal DG allocation methods in radial distribution systems based on sensitivity approaches. International Journal of Electrical Power \& Energy Systems, 53, 450-467.

Muttaqi, K. M., Le, A. D. T., Aghaei, J., Mahboubi-Moghaddam, E., Negnevitsky, M., \& Ledwich, G. (2016). Optimizing distributed generation parameters through economic feasibility assessment. Applied Energy, 165, 893-903.

Niknam, T., Taheri, S. I., Aghaei, J., Tabatabaei, S., \& Nayeripour, M. (2011). A modified honey bee mating optimization algorithm for multiobjective placement of renewable energy resources. Applied Energy, 88(12), 4817-4830.

Payyala, S. L., \& Green, T. C. (2006). Sizing of distributed generation plant through techno-economic feasibility assessment.

Penangsang, O., Amanullah, M. A., \& Aryani, N. K. (2018). Distributed generation (DG) placement for reducing power losses on radial distribution system using k-means clustering method. ARPN Journal of Engineering and Applied Sciences, 13(5), 1570-1577.

Pereira, B. R., Martins Da Costa, G. R. M., Contreras, J., \& Mantovani, J. R. S. (2016). Optimal distributed generation and reactive power allocation in electrical distribution systems. IEEE Transactions on Sustainable Eneray, 7(3), 975-984.

Rao, R. S., Ravindra, K., Satish, K., \& Narasimham, S. V. L. (2013). Power loss minimization in distribution system using network reconfiguration in the presence of distributed generation. IEEE Transactions on Power Systems, 28(1), 317-325.

Saha, G., \& George Fernandez, S. (2016). Optimal placement of distributed generation in a distribution system using hybrid big brunch and big crunch algorithm. International Journal of Control Theory and Applications, 9(16), 7789-7799.
Singh, R. K., \& Goswami, S. K. (2009). Optimum siting and sizing of distributed generations in radial and networked systems. Electric Power Components and Systems, 37(2), 127-145.

Singh, A. K., \& Parida, S. K. (2016). Novel sensitivity factors for dg placement based on loss reduction and voltage improvement. International Journal of Electrical Power and Energy Systems, 74, 453-456.

Sudabattula, S. K., \& Kowsalya, M. (2016). Flower pollination algorithm based optimal placement of solar based distributed generators in distribution system. International Journal of Renewable Energy Research, 6(4), 1232-1241.

Sultana, U., Khairuddin, A., Mokhtar, A. S., Qazi, S. H., \& Sultana, B. (2017). An optimization approach for minimizing energy losses of distribution systems based on distributed generation placement. Jurnal Teknologi, 79(4), 87-96.

Sultana, U., Khairuddin, A. B., Mokhtar, A. S., Zareen, N., \& Sultana, B. (2016). Grey wolf optimizer based placement and sizing of multiple distributed generation in the distribution system. Energy, 111, 525-536.

Suresh, M. C. V., \& Belwin Edward, J. (2017). Optimal placement of distributed generation in distribution systems by using shuffled frog leaping algorithm. ARPN Journal of Engineering and Applied Sciences, 12(3), 863-868.

Suresh, M. C. V., \& Belwin, E. J. (2018). Optimal DG placement for benefit maximization in distribution networks by using dragonfly algorithm. Renewables: Wind, Water, and Solar, 5(1), 4

Tanwar, S. S., \& Khatod, D. K. (2016). Techno-economic analysis of dg siting and sizing in a balanced radial distribution system.

Tanwar, S. S., \& Khatod, D. K. (2017). Techno-economic and environmental approach for optimal placement and sizing of renewable DGs in distribution system. Energy, 127, 52-67.

Tarôco, C. G., Takahashi, R. H. C., \& Carrano, E. G. (2016). Multiobjective planning of power distribution networks with facility location for distributed generation. Electric Power Systems Research, 141, 562-571.

Táutiva, C., Cadena, Á., Rodríguez, F. (2009). Optimal placement of distributed generation on distribution networks.

Viral, R., \& Khatod, D. K. (2012). Optimal planning of distributed generation systems in distribution system: A review. Renewable and Sustainable Energy Reviews, 16(7), 5146-5165.

Wang, G.-G., Deb, S., \& dos Coelho, L. S. (Dec 2015). Elephant herding optimization. In 2015 3rd International Symposium on Computational and Business Intelligence (ISCBI). IEEE.

Wang, C., \& Nehrir, M. H. (2004). Analytical approaches for optimal placement of distributed generation sources in power systems. IEEE Transactions on Power Systems, 19(4), 2068-2076.

Warid, W., Hizam, H., Mariun, N., \& Abdul-Wahab, N. I. (2017). A sensitivity based methodology for optimal placement of distributed generation in meshed power systems. International Journal of Simulation: Systems, Science and Technology, 17(41), 44.1-44.8.

Yammani, C., Maheswarapu, S., \& Matam, S. K. (2016a). A multi-objective shuffled bat algorithm for optimal placement and sizing of multi distributed generations with different load models. International Journal of Electrical Power and Energy Systems, 79, 120-131.

Yammani, C., Maheswarapu, S., \& Matam, S. K. (2016b). Optimal placement and sizing of distributed generations using shuffled bat algorithm with future load enhancement. International Transactions on Electrical Energy Systems, 26(2), 274-292.

Zhang, C., Li, J., Zhang, Y. J., \& Xu, Z. (2018). Optimal location planning of renewable distributed generation units in distribution networks: An analytical approach. IEEE Transactions on Power Systems, 33(3), 2742-2753.

\section{Publisher's Note}

Springer Nature remains neutral with regard to jurisdictional claims in published maps and institutional affiliations. 